\title{
Performances Assessment of Wastewater Treatment Plant in Boujaâd City, Khouribga Province, Morocco
}

Kamal Ait Ouhamchich, Abdelkrim Arioua, University Sultan Moulay Slimane,

Faculty of Sciences and Technologies, Beni Mellal, Morocco

Mustapha Lbayny,

National Office of Electricity and Drinking Water, Khouribga, Morocco

Ismail Karaoui,

Khalid El Habbari,

University Sultan Moulay Slimane,

Faculty of Sciences and Technologies, Beni Mellal, Morocco

Abdelkhalek El Amrani Idrissi,

Oum Er-Rbia Hydraulic Basin Agency of Management,

Beni Mellal, Morocco

Mohamed Hssaisoune,

Abdelali Boulli,

Driss Elhamdouni,

Fatima Ezzahra Elfiraoui,

University Sultan Moulay Slimane,

Faculty of Sciences and Technologies, Beni Mellal, Morocco

Doi: 10.19044/esj.2018.v14n27p193 URL:http://dx.doi.org/10.19044/esj.2018.v14n27p193

\section{Abstract}

The wastewater purification is a complicated and costlier operation if it not well chosen. Contrariwise, it could be simple and cheaper if the treatment system respect the environmental conditions and under international standards. To purify its wastewater, Boujaâd City chose to use the natural lagooning system. To verify the ability of this system, our study focuses on assessing the performances of this system to purify Boujaad city wastewater. For this reason, this study is based on the physicochemical monitoring of raw and purified water, both spatially and temporally, to detect and determine the percentage of pollution abatement in this wastewater treatment plant. According to the results, the quality of wastewater treatment plant rejection is conforming to the national and international standards. Here, the biochemical oxygen demand (BOD), chemical oxygen demand (COD), and suspended 
solids (SS) parameters reached $69 \%, 66 \%$, and $86 \%$ respectively. The results obtained show that the purification operation in Boujaad wastewater treatment plant was adequate.

Keywords: Wastewater treatment plant, Natural lagooning, Purifying performance, Boujaâd City

\section{Introduction}

Moroccan climate varies from sub-wet in the North, semi-arid to arid in the center, and Saharan in the South. However, this results to a high demand of water for consumption and irrigation (especially in arid to semi-arid zones) that exceeds the available water resources (Dssouli, EL Halouani, \& Berrichi, 2006). Among all Mediterranean countries, Morocco is one of the regions that show a deficit and is at the edge of scarceness. The consumption of water has already attained a level in which it can be classified in the category of water stress (700 $\mathrm{m}^{3} / \mathrm{cap} /$ year) (Assem, El Hafid, Haloui, \& El Atmani, 2006). In 2020 , it has been forecasted that $35 \%$ of the population will undergo severe stress fixed in $500 \mathrm{~m}^{3} / \mathrm{cap} /$ year (Dssouli et al., 2006).

In this rare situation, the imbalance must be compensated through the recovery and the reuse of wastewater. Thus, this introduces an additional source of water, especially for agricultural use (more than $85 \%$ of the resource) (Meehan, Ormerod, \& Moore, 2013; Condom, Lefebvre, \& Vandome, 2012). On the other hand, wastewater in an environment, without any treatment and/or prior purification, results to harmful effects to the population (diseases, epidemiological tracks); the disturbance of the ecosystem from an environmental perspective; and it is hazardous to man's health due to pollution (Lhadi et al., 1998).

There are almost 113 wastewater treatment plants in our country and most of them are not working or are not functioning effectively (National Office of Electricity and Drinking Water). Therefore, this is attributed to the weakness of the purification performances of these systems under several pressures. The malfunction of wastewater treatment plants causes some imbalances in purification level. Accordingly, badly purified wastewater is cross-posted directly either in rivers and/or in sea, causes enormous ecological problems, or results to a reuse in the agriculture of fruit trees without any limitation or surveillance. The aim of this study is to evaluate the performance level of wastewater treatment plant of Boujaâd City in order to mitigate - if it possible - the constraints encountered during the wastewater treatment stages. 


\section{Materials and Methods}

\subsection{Study Area}

Boujaâd City is located at the central region of Morocco halfway between Khouribga and Béni Mellal. Hence, it is located at about $56 \mathrm{~km}$ East of Khouribga. The wastewater treatment plant of Boujaâd City is located in the Southwest border of the city perimeter as shown in Figure 1. This wastewater treatment plant ensures the purification of wastewaters of domestic origin as long as there is no industrial activity in the city. It covers an area of 26 hectares and is composed of 24 basins. In addition to the six sewage sludge drying beds, the wastewater treatment plant include six anaerobic basins of primary treatment, six optional basins of secondary treatment, and six maturation basins as illustrated in Figure 2.

To get an idea of the future evolution of the population, Table 1 shows the population projections of the city beyond the year 2034 with a fixed growth rate of 2\% using the Equation (1) (Noel, 2011):

$$
\operatorname{Pop}(x)=\operatorname{Pop}(\text { initial }) \times(1+G r)^{\text {year }(x) \text {-initial year }}
$$

Where:

Pop: Population

$\mathrm{x}$ : Projected year

Gr: Growth rate

Table 1. Forecast of the population of Boujaâd city (High Commission for Planning, Morocco, 2004 and 2014)

\begin{tabular}{|c|c|c|c|c|c|}
\hline Year & 2004 & 2014 & 2024 & & 2034 \\
\hline Growth rate \% & \multicolumn{2}{|c|}{$2 \%$} & $2 \%$ & $2 \%$ & \\
\hline Population (resident) & 40513 & 46893 & 57162 & & 69680 \\
\hline
\end{tabular}




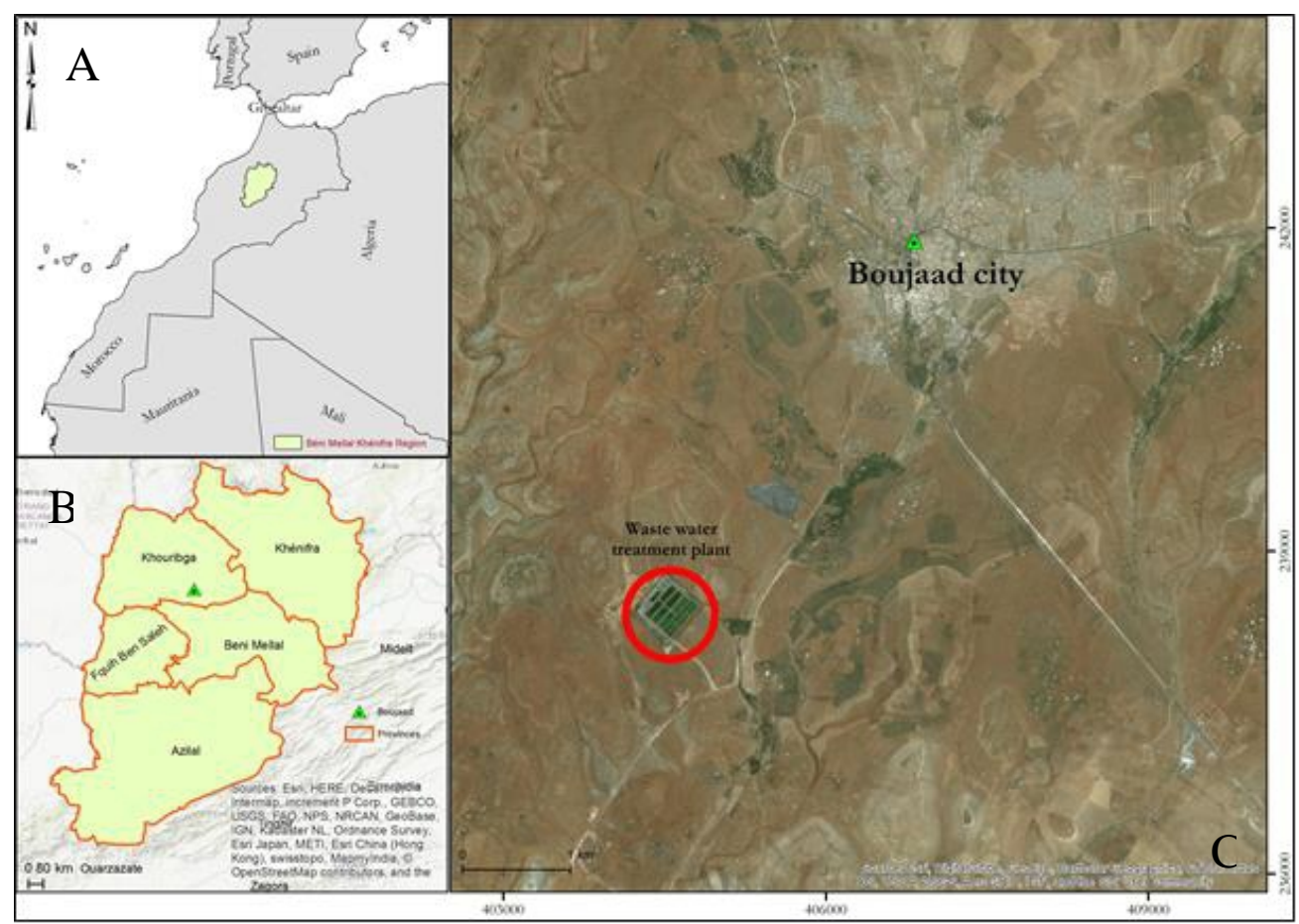

Figure 1. A: Study area in national scale, B: Study area in regional scale, and C: Study area in local scale

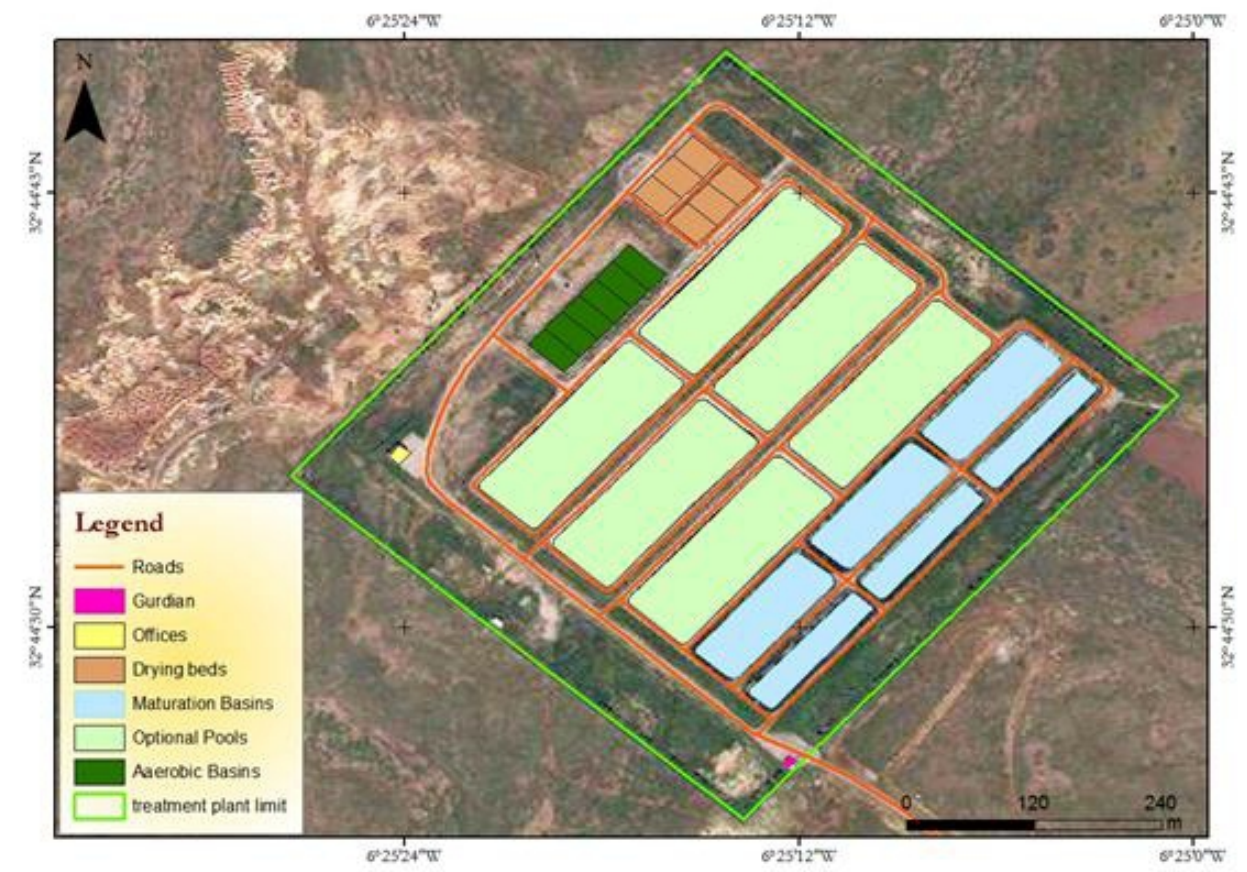

Figure 2. Various structures of the Boujaâd Wastewater Treatment Plant 


\subsection{Methodology}

To conduct this study, a field trip was made to the study area. This is in a bid to understand our work environment in the wastewater treatment plant and to collect data from different sources. Hence, these are summarized by the following steps:

- Field Trips: Several outputs have been programmed to collect different types of data (wastewater treatment plant description, sewerage diagnostic).

- Administrations and agencies that are working in the field visits (Regional Directorate of the National Office for Electricity and Drinking Water, Municipality of Boujaâd etc.) in order to obtain inspiration from their experiences.

- Perform meetings with the managers of the wastewater treatment plant in order to discuss all the accurate problems that disrupt the operation of this unit.

- Office Work: The purpose here is to process and analyze the recovered data from the administrations and those obtained in the field. Elaborate maps, diagrams, curves etc. have been developed to facilitate the understanding of the problem treated.

\subsection{Moroccan Rejection Norms}

Wastewaters are characterized by physicochemical and bacteriological parameters. These parameters are used to determine their possible origin and know the importance of their pollution load. Until they are rejected in the natural environment and do not degrade, they must obey standards established to protect the receiver against pollution. In doing this, they are transported to a wastewater treatment plant where they undergo several phases of treatment. According to Moroccan standards (Djeddou, Bachirb, \& Martaud, 2013; Gamar et al., 2017), the maximum limits values for the effluents are shown in Table 2.

Table 2. Values specific release limits applicable to urban sewage spills

\begin{tabular}{c|c}
\hline Parameters & Specific limit values of domestic rejection \\
\hline$B O D 5$ in $\mathrm{mg} d^{\prime} \mathrm{O}_{2} / \mathrm{L}$ & 120 \\
\hline$C O D$ in $\mathrm{mg} \mathrm{d} \mathrm{d}_{2} / \mathrm{L}$ & 250 \\
\hline $\mathrm{SS}$ in $\mathrm{mg} / \mathrm{L}$ & 150 \\
\hline mg: milligram
\end{tabular}




\section{Results and Discussion}

\subsection{Wastewater Treatment Plant Characteristics}

\subsubsection{Biochemical Oxygen Demand in Five Days (BOD5)}

Due to the lack of 2015 and 2016 data for this parameter, our focus is on 2014 data in order to assess the content of biodegradable organic matter and to determine the yield of this parameter.

Biochemical oxygen demand in five days (BOD5), expressed in $\mathrm{mg}$ of oxygen per liter, allows the assessment of biodegradable organic matter in water. Specifically, this parameter measures the amount of oxygen required to destroy organic matter through aerobic oxidation phenomena (Abouelouafa, El halouani, Kharboua, \& Berrichi, 2002).

The BOD5 concentrations show that the entrance of the wastewater treatment plant varies between $130 \mathrm{mg} / \mathrm{L}$ and $260 \mathrm{mg} / \mathrm{L}$. This can be seen in Figure 3 below. The average values in the output ranges between $70 \mathrm{mg} / \mathrm{L}$ and $80 \mathrm{mg} / \mathrm{L}$ with an average of $73.33 \mathrm{mg} / \mathrm{L}$. These values of BOD5 at the output conform to specific domestic release limits values.

Furthermore, this parameter is a good indicator of the biodegradable organic matter content of natural, polluted or wastewater (Belghyti et al., 2009). It is used to:

- Quantify the organic pollutant load of water.

- Assess the impact of a rejection on the natural environment (all rejected biodegradable organic matter will result in consumption of oxygen during the self-purification processes).

- Evaluate the intensity of treatment necessary for the purification of a discharge by a biological process.

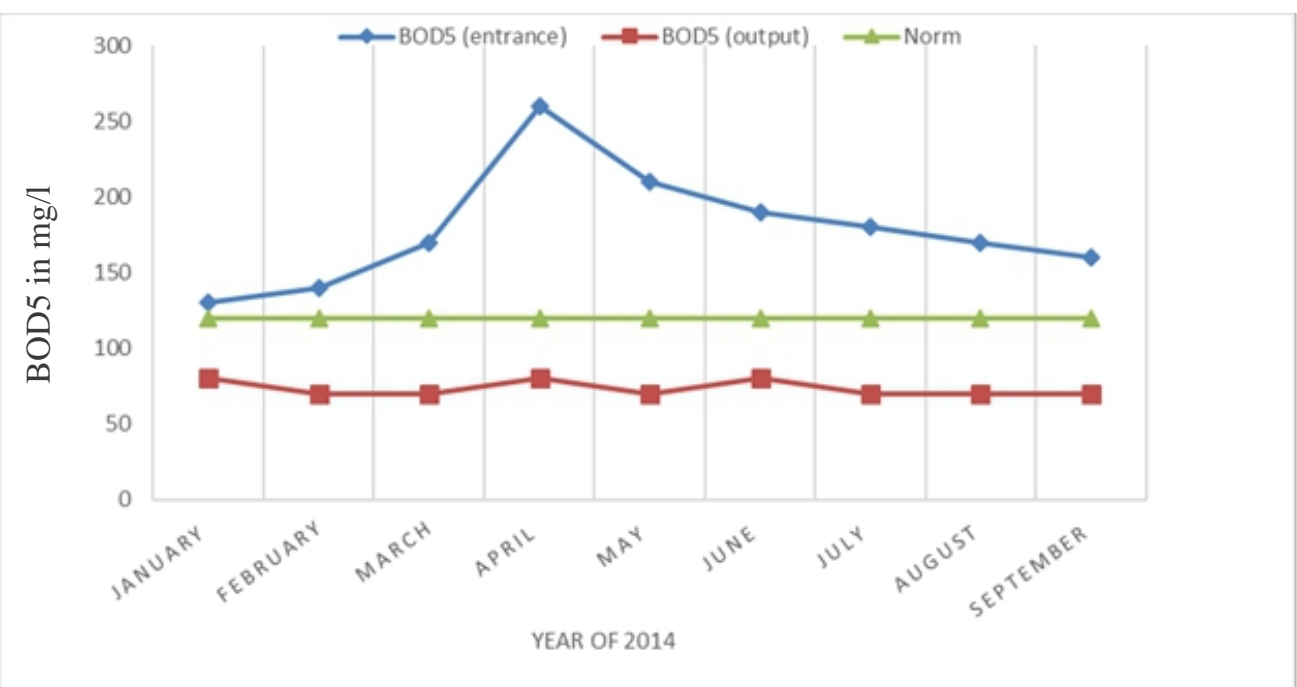

Figure 3. BOD5 variation at the entrance and exit of the wastewater treatment plant 


\subsubsection{Chemical Oxygen Demand in Five Days (COD5)}

The chemical oxygen demand in five days (COD5) is expressed in $\mathrm{mgO}_{2} / \mathrm{L}$, and it corresponds to the amount of oxygen required for chemical degradation in five days. Moreover, this can be seen under defined conditions of the organic or inorganic matter contained in the water (Bouchouata, El kharrim \& Bounouirar, 2009). It therefore represents the total content of water in oxidizable materials.

Consequently, the COD5 allows the appreciating of the concentration of organic or mineral matter, dissolved or suspended in water, through the amount of oxygen necessary for their total chemical oxidation.

The COD5 values at the wastewater treatment plant entrance ranged from $270 \mathrm{mg} / \mathrm{L}$ to $580 \mathrm{mg} / \mathrm{L}$. In addition, the output values vary between 170 $\mathrm{mg} / \mathrm{L}$ and $210 \mathrm{mg} / \mathrm{L}$ with an average of $184.44 \mathrm{mg} / \mathrm{L}$ as shown in the Figure 4. Thus, these values are consistent with values of the specific domestic release limits.

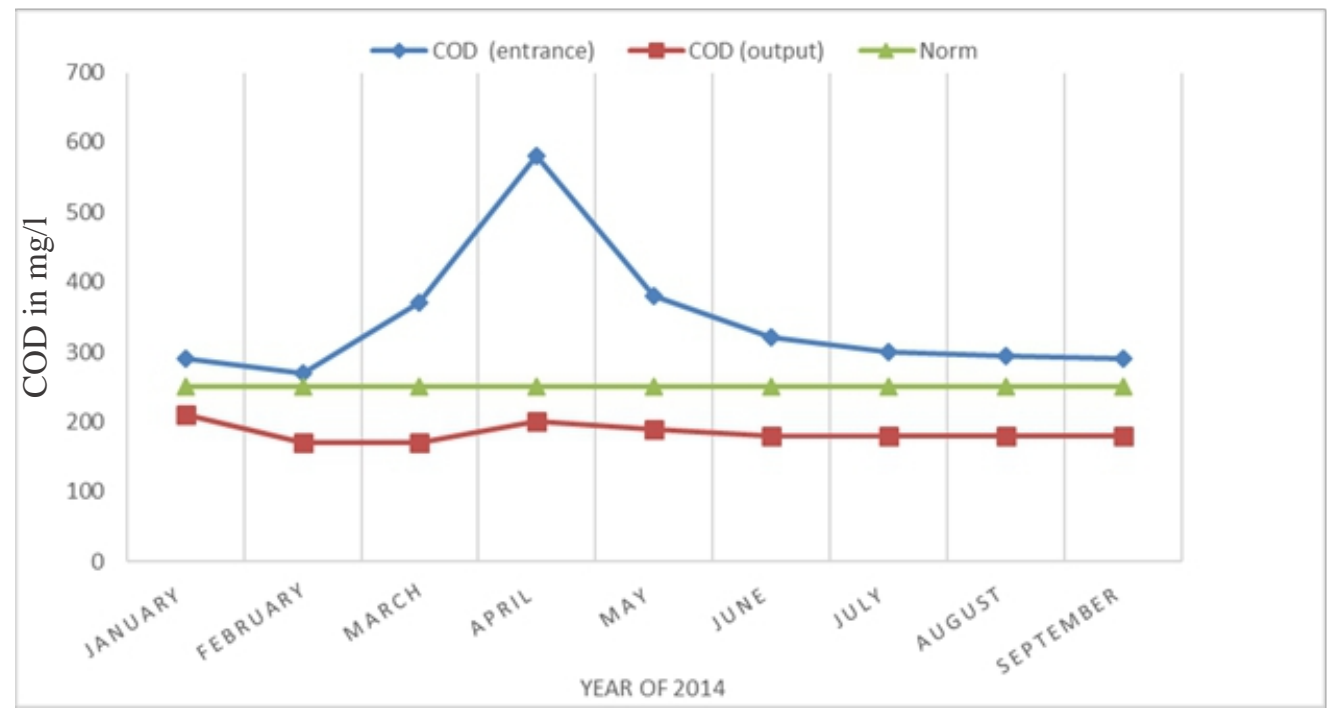

Figure 4. COD variation at the entrance and output of the wastewater treatment plant

\subsubsection{Suspended Solids (SS)}

Suspended matter, expressed in $\mathrm{mg} / \mathrm{l}$, represents all mineral and organic particles contained in wastewater. The knowledge of the concentration of the colloidal elements in wastewater is necessary in the assessment of the impact of pollution on the aquatic environment (Chaouki et al., 2013; Nacir et al., 2010).

The quantity of the suspended material at the wastewater treatment plant entrance varies between $120 \mathrm{mg} / \mathrm{L}$ and $280 \mathrm{mg} / \mathrm{l}$. This is with an average of $173.33 \mathrm{mg} / \mathrm{L}$ as shown in Figure 5 . The output concentration ranged from $30 \mathrm{mg} / \mathrm{L}$ to $60 \mathrm{mg} / \mathrm{L}$ with an average of $42.22 \mathrm{mg} / \mathrm{L}$. Therefore, these values 
of the suspended matter at the output are conforming within the range of the specific limit values of domestic rejection.

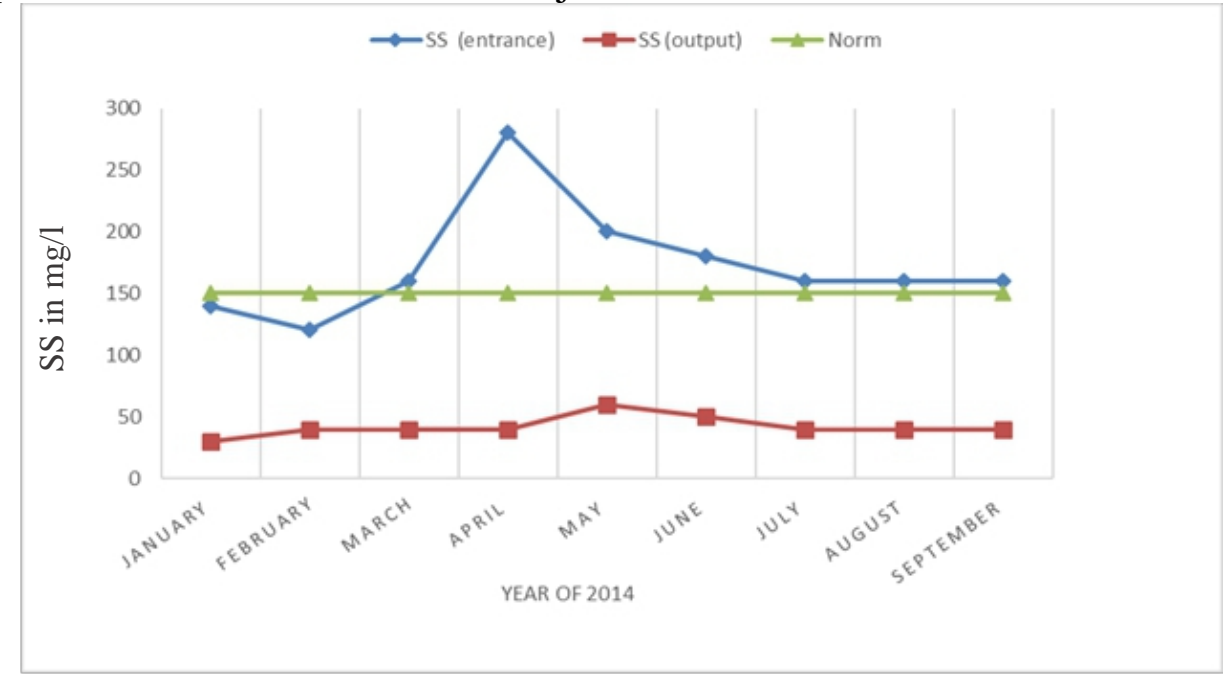

Figure 5. Suspended solids variation at the entrance and output of wastewater treatment plant

\subsection{Purification Yields}

\subsubsection{Biochemical Oxygen Demand (BOD5)}

Figure 6 shows the interval of BOD5 abatement during year 2014. This yield is fair to fairly well. It varies between $38 \%$ and $69 \%$ during the months of the year, especially in the month of April. Hence, this coincides with the period bloom and important development of algae (spring season). During this period of the year, the yield of the optional basin is maximal.

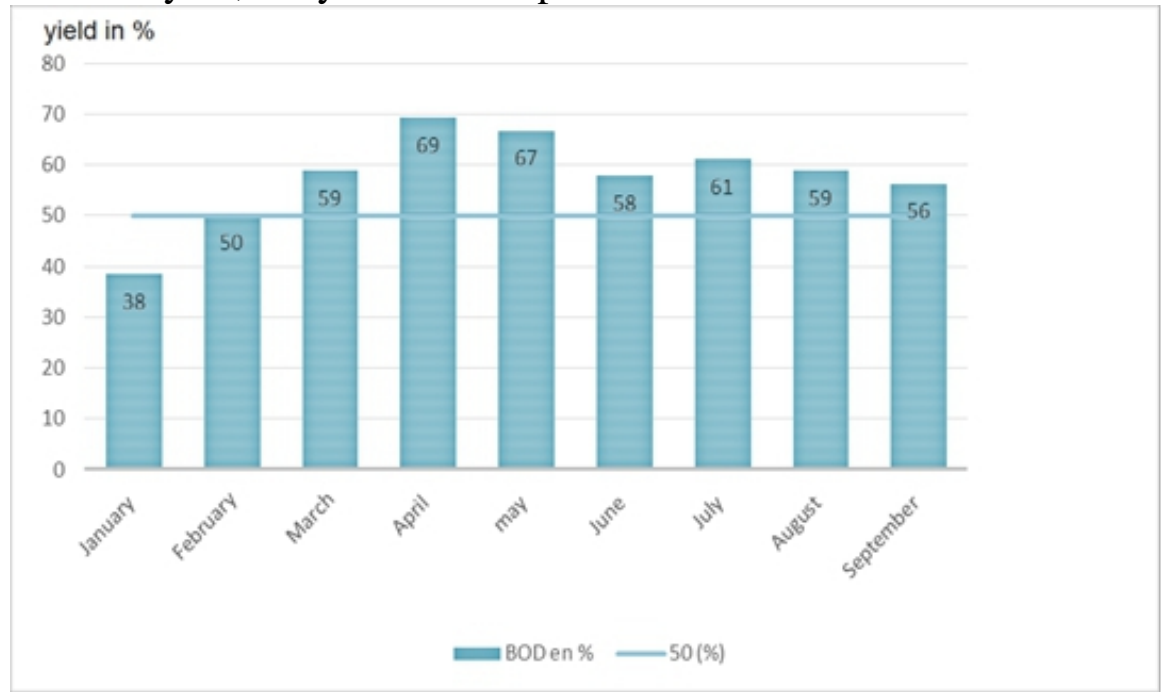

Figure 6. Performance of the wastewater treatment plant against the BOD5 in 2014 


\subsubsection{Chemical Oxygen Demand (COD)}

Figure 7 shows the yield of COD abatement during the year 2014. The COD yield is slightly low, ranging from 28\% (February) to 66\% (April). A purification yield of a chemical parameter, such as that one that shows that the purification is incomplete as long as the yield exceeds 50\%, was recorded except during the month of March, April, and May. The COD yields declined in the other months and are generally altered by the presence of green algae in the treated effluent.

In terms of purification yield, the seasonal influence is very marked. It is medium in spring, and low in other seasons. The analyses carried out in the entrance and the outputs of the wastewater treatment plant gave acceptable results. However, this indicates that purified waters have a physical and chemical characteristic in standard releases. In addition, a parasite water of Ain Sheikh Source water and rainwater disturbs its purification power.

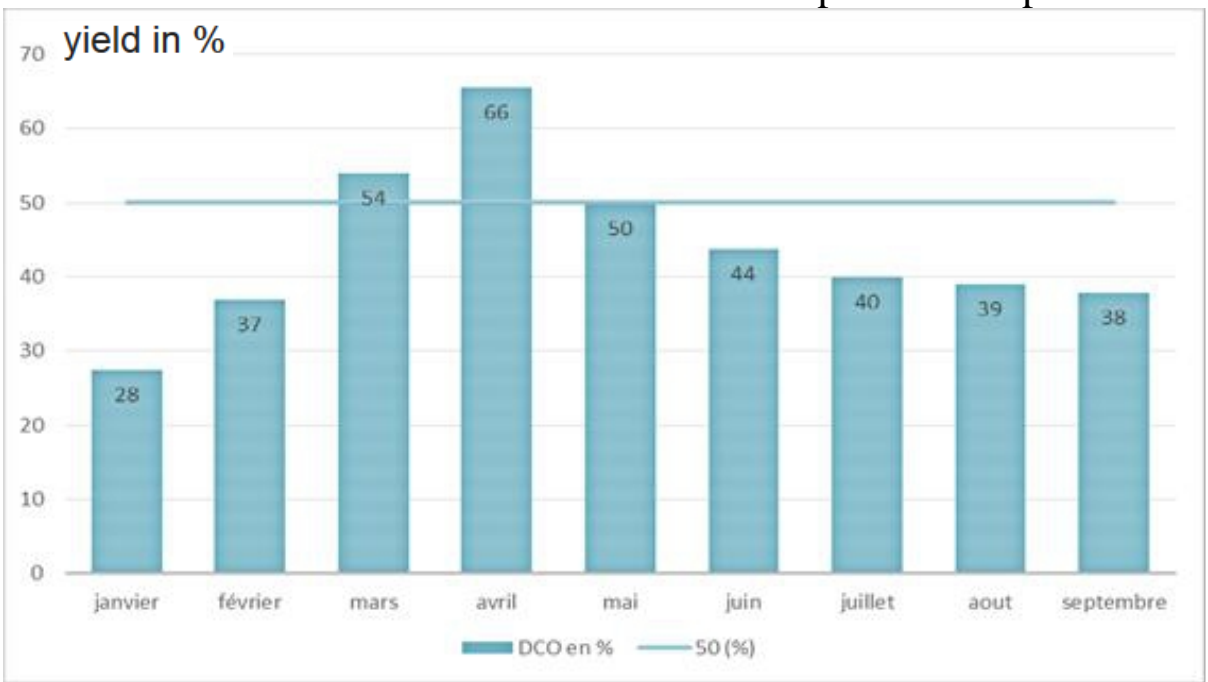

Figure 7. Efficiency of the wastewater treatment plant against the COD in 2014

\subsubsection{Suspended Solids (SS)}

Figure 8 shows the yield of suspended solids abatement during the year 2014. Monthly yields of suspended material are generally good. However, they are between $67 \%$ and $86 \%$ due to the primary treatment that allows for a strong sedimentation and mineralization of organic matter by anaerobic digestion.

The remaining part expresses the high charge of planktonic organisms that are developed in the second and third basins. However, they do not represent any pollution in itself, as long as the receiving environment may accept this load of living organic matter. For this reason, it is necessary to avoid releases in too small environments, under the risk of causing 
eutrophication phenomena. In order to overcome the problem, sand-bed filtering systems can be used to reduce the load in suspended solids.

Based on wastewater treatment plant performances assessment, and on the quality verification of the leaving effluent from station, taking into account the releases standard, the result shows their correspondence in regards to domestic discharges standard. Azami et al. (2015) in their study of the analysis of the Azilal City sewage wastewater, between August 2013 and May 2015, shows that there is an important fluctuation of some parameter (BOD5, SS etc.). The values obtained are higher than wastewater rejection standards recommended by World Health Organization (WHO). Otherwise, the purification results obtained by Boutayeb, Bouzidi, and Fekhaoui (2013) in the Chaouia Ouardigha region yields an observed range between 74 to $92 \%$ as a deduction for BOD5. This average yield varies between 63 and $83 \%$ for COD5, and between 54 and $87 \%$ for suspended solids (SS). However, this explains that the purification performances is low and is variable. Also, it remains season-dependent for nitrogen and phosphorus.

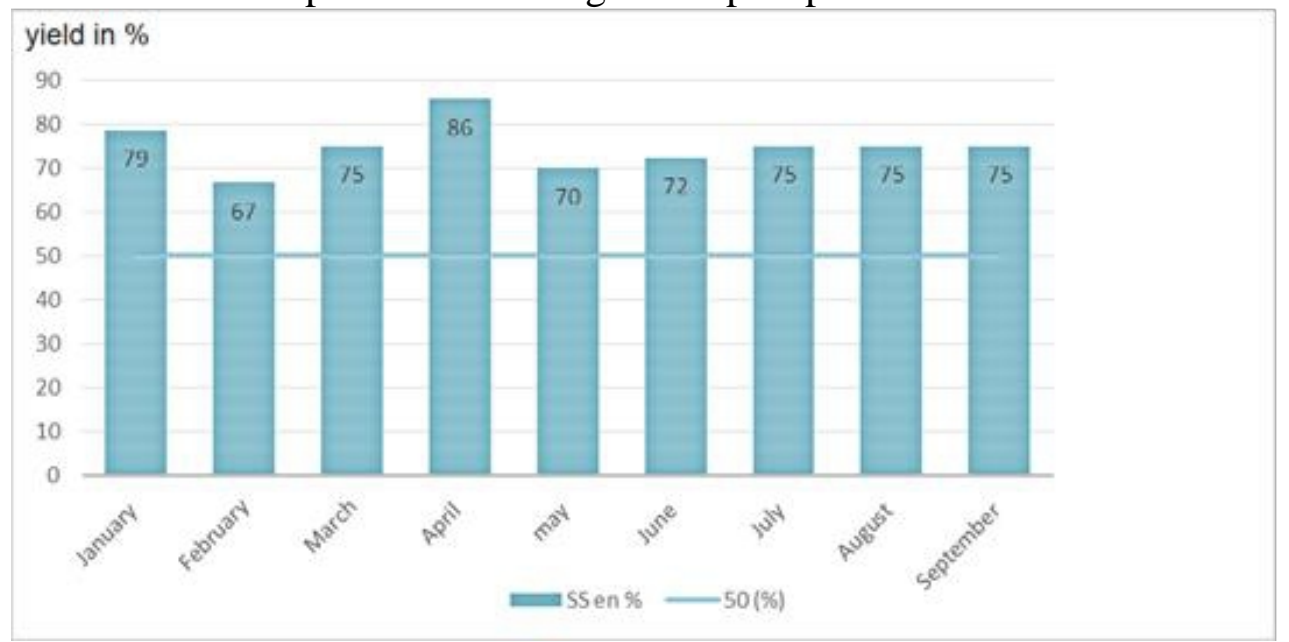

Figure 8. Performance of the wastewater treatment plant against the SS in 2014

\section{Conclusion}

Monitoring the performance of Boujaâd wastewater treatment plant has been done to determine the pollution degree of raw water. It also aims to evaluate the effectiveness of the treatment processing, and to have an idea on the functioning of the wastewater treatment plant. Furthermore, the follow-up of the performance of the waste water treatment plant gave the following conclusion:

- The purification performance has improved with the new technique of natural lagooning. In fact, yields reached values of $69 \%, 66 \%$ and $86 \%$ respectively for BOD5, COD5 and SS. Thus, this means that the operation at the level of the water treatment station is acceptable, and 
may improve if we get rid of some disturbances (deviation of raw sewage, dilution, and theft of water in the upstream of the wastewater treatment plant etc.).

- The quality of the water purified by the wastewater treatment plant complies with the specific limits of domestic releases as cited in Table 2. However, they remain unfit and restrictive for any specific use including their reuse in drinking water or in the irrigation of fruit crops. This is because it must meet the quality standard of purified wastewater for irrigation.

- The conditions of treatment and the yields obtained are not very satisfactory for further exploitation of this purification plant. Therefore, it is imperatively recommended that solutions should be proffer to these types of disturbances.

- Wastewater treatment efforts are still very much lower than the actual needs. Sanitation studies, even if they adopt an integrated approach to the collection of purification, reuse, are not followed by a complete achievements. In the national water context, wastewater should be considered as a non-negligible resource to be showcased in a controlled environment. Wastewater treatment for reuse in agriculture would protect the natural environment and provide significant potential for recovery.

\section{References:}

1. Abouelouafa, M., El halouani, H., Kharboua, M., \& Berrichi, A. (2002). Agronomic and Veterinary Institute acts, 22, 143-150.

2. Assem, N., El Hafid, L., Haloui, B., \& El Atmani, K. (2006). Sécheresse, 17, 499-505.

3. Azami Idrissi, Y., Alemad, A., Aboubaker, S., Daifi, H., Elkharrim, K., \& Belghyti, D. (2015). International Journal of Innovation Science and Research, 11, 556-566.

4. Belghyti, D., El guamri, Y., Ztit, G., Ouahidi, M. L., Joti, M. B., Harchrass, A., Amghar, H., Bouchouata, O., El kharrim, K., \& Bounouira, H. (2009). Afrique Science, 05, 199216.http://www.afriquescience.info/document.php?id=1490

5. Boutayeb, M., Bouzidi, A., \& Fekhaoui, M. (2013). Nature \& Technology Journal, 08 49-53.

6. Chaouki, I., Mouhir, L., Souabi, S., Fekhaoui, M., \& El abidi, A. (2013). Afrique Science, 09, 91-102.

7. Condom, N., Lefebvre, M., \& Vandome, L. (2012). Blue Plan Papers, ISBN 978-2-912081-30-8 63. https://www.cairn.info/revue-scienceseaux-et-territoires-2013-2-page-54.htm

8. Directorate of National Office of Electricity and Drinking Water 
(2017). http://www.agrimaroc.ma/taux-epuration-eaux-usees/

9. Djeddou, M., Bachirb, A., \& Martaud, M. (2013). Water, Waste \& Environment (EDE4), 18.

10. Dssouli, K., EL Halouani, H., \& Berrichi, A. (2006). Biologie \& Health, 6, 51-58.

11. Gamar, A., Khiya, Z., Zair, T., El Kabriti, M., Bouhlal, A., \& El Hilali, F. (2017). International Journal of Scientific \& Technology Research, 6, 166-171. https://doi.org/10.26872/jmes.2018.9.3.104

12. Lhadi, E.K., Damnati, N., Guessir, H., Handoufe, A., \& Benchokroun, T. (1998). Agronomic and Veterinary Institute acts, 18 213-225.

13. Meehan, K., Ormerod, K.J., \& Moore, S.A. (2013). Water Alternatives Journal 6, 67-85.

14. Nacir, S., Ouazzani, N., Vasel, J.L., Jupsin, H., \& Mandi, L. (2010). Water Science Journal, 23(1) 57-72. http://dx.doi.org/10.7202/038925ar

15. Noel, P. (2011). Project Memory, international institute of water and environment engineering. 